\title{
Problems and Countermeasures in College English Audiovisual and Speaking Teaching Mode
}

\author{
Xiao Limei \\ (Army Infantry College of PLA, Nanchang 330103)
}

Keywords: English major; Audiovisual and Speaking Curriculum; problem; countermeasure

\begin{abstract}
Foreign language learning has four basic skills: listening, speaking, reading and writing. Among these four skills, listening and reading are inputandthe basis of speaking and writing. The correctness and the size of input directly determine the ability and quality of output. Therefore, foreign language learning requires a large amount of real corpus. The way of "working behind closed doors" is not feasible. Only from the real corpus can you understand how native speakers use a language. However, for most Chinese English learners, there are not many opportunities to truly immerse themselves in an English environment and communicate with native English speakers. This is the premise for the English language majors to open the English Audiovisual and Speaking Curriculum. In this regard, this paper analyzes the problems existing in college English audiovisual and speaking teaching and proposes corresponding strategies to explore how to make the curriculum reach the expected teaching goal and promote the prosperity and development of college English major.
\end{abstract}

\section{Introduction}

With the advancement and development of modern information technology and multimedia means, it's possible for information technology entering the field of teaching. In this context, the novel teaching mode of college Audiovisual and Speaking Curriculum has emerged as the times require, and is widely used in English teaching. The college Audiovisual and Speaking Curriculum is an effective integration of information technology and English teaching. It completely subverts the traditional blackboard teaching method of "blackboard + chalk". In the information technology environment, it moves the content of extracurricular activities into the Audiovisual and Speaking Curriculum. Multimedia and network, visual images, audio-visual effects and language exchanges are combined and integrated. Listening is the forerunner and video images are used as an aid to provide students with a more flexible and diverse learning style. However, in the teaching of information technology, there will be some problems that affect the development of teaching. In this regard, this paper analyzes the current situation of college English audiovisual and apeakingteaching under the background of information technology, and makes improvements to the problems that arise, in order to provide reference for future English-based audiovisual and speaking teaching.

\section{The advantages of college English audiovisual and speaking teaching}

A large number of psychological research experiments have confirmed that: $83 \%$ of information access channels of human is from vision, $11 \%$ comes from hearing, 3.5\% comes from smell, $1.5 \%$ comes from touch, and 1\% comes from taste. Therefore, the advantages of modern information technology in college English audiovisual and speaking teaching are obvious. College English audiovisual and speaking teaching under the information technology environment makes full use of digital, network, intelligent and other information technology with more information carriers. In addition to theteaching text materials on traditional paper, there are a large number of rich and diverse multimedia information, such as sound, video images, etc., as a supplement.

This novel teaching mode has got rid of the old-fashioned sense of traditional textbooks, breaking the simplification and mechanization of original teaching mode; enhancing the fun and flexibility of language learning. The application of multimedia means stimulates students' interest 
in learning and taps the potential of learning. Students are more communicative and are more likely to invest in what they have learned. The college English audiovisual and speaking teaching mode takes "visual" as the means and "listening and speaking ability" as the training goal, balancing the language output function with the language input function, fully mobilizing the learners' whole body and mind system, and the efficiencyof gaining knowledge, attention and memory retention rate are improved.

\section{The problems in English audiovisual and speaking teaching}

Over the years, English majors and graduates have good job allocation, so the society has always regarded English as a hot major, resulting in the lack of crisis awarenessand lack of urgency for the reform of college Englishfor the leaders and teachers of foreign language departments. Due to the single-subject characteristics of college English major, the structural model of college English major is mainly composed of comprehensive English curriculum, and the curriculum such as audiovisual and speaking have been placed in a secondary position for a long time. The specific problems of the college English major are related to the following aspects:

1. Outdated teaching concept

The teaching of audiovisual speaking still stays in the old frame of "teacher-centered" and "focusing on knowledge and making light of practice". [1] (48- 51) The teachers do not know enough about the audiovisual and speaking class, which results in: teaching is mainly based on the teacher's teaching, and the students are in a position of passive acceptance, ignoring the initiative and creativity of students. Even if there is language practice, it is limited to mechanical repetition, rote memorization and single sentence practice; or excessive emphasis on listening training, weakening the cultivation of other skills.

2. Less communication and interaction

Due to the problemsabove, the interactive activities between students and teachers are difficult to carry out. Each student has less opportunities to participate and display in the classroom. Without the emotional factors that are very important in the language learning process, the teacher's personality charm cannot be revealed. Teacher-student interaction and the interaction among students cannot be carried out. The subjective initiative of teachers and students in the process of teaching and learning is restrained to a certain extent, which affects the teaching effect of audiovisual speaking class to a certain extent.

3. Students' self-learning awareness is weak and their self-control ability is poor.

Since most students have adapted to the teaching mode of traditional classroom based on teacher teaching, they are accustomed to passive learning, and it is difficult to learn completely independently under the new teaching mode. Although the teacher has arranged certain learning tasks to guide the students' self-directed learning, many students only passively complete the tasks assigned by the teachers. They do not have their own study plans, nor can they reasonably plan their own study time.

4. The role of teachers in the process of self-directed learning is not clear

The reform of college English teaching needs to complete a series of changes. The content of teaching should be changed from the teaching of language points to the cultivation of students' communicative competence; the status of teachers should be changed from the instructor of knowledge to the instructor and quality monitor of practical ability; the classroom teaching mode is changed from teacher-centered mode to student-centered mode. However, because some teachers are not clear about their role in the process of self-directed learning, and because teachers do not understand the self-learning, there are two extremes: firstly, some teachers still explain too much in the self-learning classroom. The whole classroom is still centered on the teacher; secondly, some teachers think that self-learning is a students' own task, and teachers only have to arrange the learning tasks in the classroom. 


\section{The improvement countermeasures of college English audiovisual and speaking teaching under the background of information technology}

1. Enrich the content of college English audiovisual and speaking teaching with multimedia technology

Under the background of information technology era, college English teachers use multimedia equipment to teach during the teaching tasks, and make film clips and translations related to the course content into teaching short films, so that students can listen to the teacher while they are watching the film, and imitate the dubbing in the film to do the corresponding voice exercises.

2. Make full use of existing resources to create a good self-directed learning environment

There are more than 18,000 students in our campus, and the existing self-directed learning laboratory can only meet the self-directed learning requirements of the students in experimental classes. Therefore, the school should pay attention to strengthening the construction of self-directed learning environment. Firstly, integrate computer resources, and install client software for learning English in all available computers, such as computer centers, computer classrooms of various departments, and library electronic reading rooms, and attaching the English resource library to the campus network; secondly, increasing investment and build several English self-directed learning laboratories to meet the needs of students self-directed learning.

3. Introducing Internet technology to create a good intercultural communication atmosphere for students

In order to improve the intercultural English communication ability and oral expression ability of college students, English teachers must play the role of organizer and guide, which is reflected in the following two aspects: firstly, fully apply multimedia and Internet teaching tools to further make university students be engaged with relevant mass media so that they can learn about the latest English culture, such as allowing students to regularly listen to English learning websites such as "BBC" and "VOA", and arrange cross-cultural communication learning activities to enable students to understand the differences between the expression of English culture and Chinese, and then improve the students' understanding of English; secondly, carry out corresponding intercultural communication activities on campus to create a good atmosphere for English communication, and teachers can invite some international friends and students to express face to face to exercise their oral expression skills.

4. Flexible transformation of the role of teachers and students

Different teaching stages and different teaching purposes may change the role of teachers. Teachers should switch flexibly in these roles. These roles include, but are not limited to, the following: advocates, designers, organizers, leaders, interpreters/knowledge sources, evaluators, learners/investigators, participants, facilitators. Students are not passive recipients in the audiovisual and speaking class, but active participants. At each stage of teaching, students should actively think, actively cooperate and participate in teaching. Such participation includes thinking participation, emotional participation, and behavioral participation. Only with the full participation, the classroom teaching effect will be more significant.

\section{Conclusion}

Under the background of information technology development, college English audiovisual and speaking teaching has integrated the teaching mode and teaching content, and realized the optimization of English teaching. Because the teaching of college English audiovisual and speaking ability is weak in the whole college English curriculum teaching, this study focuses on how to optimize college English audiovisual and speaking teaching under the background of Internet and multimedia, whichhas important reference significancein promoting the development of college English audiovisual and speaking teachingfurther and improving the teaching level. 


\section{References}

[1]Hong L. Application of the Multimodal Discourse Analysis Theory to the Teaching of College English Listening and Speaking[J]. Ieri Procedia, 2012, 2:319-324.

[2]Zhang M Z X. Research on Double-dominant College English Viewing, Listening \& Speaking Teaching Model_-An Analysis of Correlation between Teacher Guidance and Student Dominance[J]. Journal of Beijing International Studies University, 2012.

[3]Fu X. Research on Application of information technology to the teaching of College English listening and speaking strategy[J]. Network Security Technology \& Application, 2014.

[4]Hao Y. Research on English listening-Speaking Teaching Model of Junior Middle School Based on the Information Technology[J]. Electronic Test, 2015.

[5]Wu S, Zhong Z. Application Research on Original English Movies in College English Listening and Speaking Teaching[J]. Journal of Jiangxi Radio \& Tv University, 2012.

[6]Feng W. Research on Present Conditions and Improvement Strategy of College English Listening and Speaking Teaching[C]// International Conference on Social Network, Communication and Education. 2017.

[7]Wang D, Zhang Y. A study on the flipped classroom model in college English listening and speaking teaching based on Longman Interactive English teaching platform[J]. Journal of Anshan Normal University, 2016.

[8]Dong W, Ding Y, Shi Y. Research on cooperative-based listening and speaking English teaching mode and application for fuzzy mathematics[J]. 2016, 25:01008.

[9]Zheng Z, Humanities S O. An Empirical Study of College English Listening to Improve Speaking Teaching Model Based on Chunk[J]. Journal of Chongqing Jiaotong University, 2015.

[10]Guo R, Zhao S N, Chu C Y. Practice and Research on Project-based Collaborative Learning in the Teaching of College English Listening and Speaking[J]. Value Engineering, 2015.

[11]Xiao Q H, You J. Research on college English listening and speaking teaching based on the self-study system[J]. Journal of Nanchang College of Education, 2013, 31(16):102-107.

[12]Yusu L I. On the Analysis of Teachers' Role Based on PBL Teaching Model—A Case Study of College English Listening and Speaking Course[J]. Guide of Science \& Education, 2017.

[13]Zeng Z, Yin X, Zeng X. The Effects of Cooperative Teaching Reform on Chinese English Learners' Linguistic Abilities and Non-linguistic Abilities[J]. Higher Education of Social Science, 2013.

[14]Zhang W J. A Research on the Teaching Model of English Listening and Speaking Course in Private Colleges Based on the Platform of Informationization[J]. Education Modernization, 2018.

[15]Chen X X, Dan L I. Research on College English Listening and Speaking Teaching Strategy Based on Core Literacy[J]. Journal of Hubei Correspondence University, 2018. 